\title{
POST-OPERATIVE ORAL ANTIBIOTICS IN REDUCING FREQUENCY OF SURGICAL SITE INFECTION FOLLOWING NON-PERFORATED APPENDECTOMY IN POPULATION OF SOUTH WAZIRISTAN AGENCY, PAKISTAN
}

\author{
Aftab Alam1, Aziz Ur Rehman', Dastageer Waheed², Muhammad Hamayun Khan², Waseem Ahmad², \\ Irum Bashir', Abd Ullah', Irfan Ullah Khan' \\ Departments of Surgery, ${ }^{1}$ Agency HQ Hospital, Wana, ${ }^{2}$ DHQT Hospital, D.I.Khan, Pakistan
}

\begin{abstract}
Background: Acute appendicitis is most frequent cause of acute abdomen in younger population, and surgical site infection (SSI) is commonest complication of appendectomy. The objective of this trial was to compare the efficacy of post-operative oral antibiotics versus placebo in reducing the frequency of surgical site infection (SSI) following appendectomy for non-perforated appendicitis in population of South Waziristan Agency, Pakistan.

Materials \& Methods: The randomized placebo trial was conducted at Agency Headquarter Hospital, Wana, South Waziristan, Pakistan from October 1, 2016 to November 18, 2018. One hundred fifty (150) patients were randomly allocated into two groups, 75 in experimental group, to whom antibiotics were given and 75 in placebo group, to whom antibiotics were not given. Age groups and presence of SSI were two variables, being on nominal scale, were described by count and percentage with $\mathrm{Cl}$ at $80 \% \mathrm{CL}$. McNemar chi-square test was applied to test the hypothesis to see the significance of difference between the experimental and placebo groups in terms of frequency of SSI at alpha .05.

Results: SSI was present in nine $(12 \%, 80 \% \mathrm{Cl} 7.19-16.80 \%)$ out of 75 cases in experimental group and in 12 $(16 \%, 80 \% \mathrm{Cl} 10.57-21.42 \%)$ out of 75 cases in placebo group. McNemar chi-square test showed no significant difference between the experimental and placebo groups in terms of frequency of $S S I(p=.2482)$.

Conclusion: The results are comparable for post-operative oral antibiotics versus placebo in reducing the frequency of surgical site infection (SSI) following appendectomy for non-perforated appendicitis in population of South Waziristan Agency, Pakistan.

KEY WORDS: Appendicitis; Acute Appendicitis; Antibiotics; Appendectomy; Nonperforated Appendicitis; Surgical Site Infection; Efficacy.

Cite as: Alam A, Rehman AU, Waheed D, Khan MH, Ahmad W, Bashir I, Ullah A, Khan IU. Post-operative oral antibiotics in reducing frequency of surgical site infection following non-perforated appendectomy in population of South Waziristan Agency, Pakistan. Gomal J Med Sci 2021 Apr-Jun; 19(2):53-7. https://doi.org/10.46903/gjms/19.02.936
\end{abstract}

\section{INTRODUCTION}

1.1 Background: Appendectomy is in the top list of most frequently performed emergency surgical procedures globally. Using perioperative antibiotics and aseptic care, surgical site infection (SSI) is still the most common complication. ${ }^{1}$

\section{Corresponding Author:}

Dr. Aftab Alam

District Surgeon

Agency HQ Hospital, Wana, Pakistan

E-mail: aftabarki@gmail.com

Date Submitted: $\quad 16-02-2021$

Date Revised: 23-03-2021

Date Accepted: $\quad 30-03-2021$
Bahar, et al. ${ }^{2}$ from Mashhad, Iran showed in his study published in 2010 that surgical site infection (SSI) occurred in $2.97 \%$ cases in simple appendicitis and $4.5 \%$ in complicated appendicitis group.

Acute appendicitis is most common cause of acute pain abdomen necessitating surgical intervention. Postoperative antibiotics are globally prescribed for complicated appendicitis; no agreement is there to use these in nonperforated cases to prevent SSI. ${ }^{3}$

Rafiq, et al. ${ }^{4}$ from Peshawar, Pakistan did not find any statistical significant difference in rate of SSI for NPA treated with single preoperative dose cefuroxime sodium and metronidazole and those treated with both single dose of pre and single dose of postoperative antibiotics. 
Mui, et al. ${ }^{5}$ from Hong Kong, found no difference for SSI for NPA between three antibiotic regimens i.e. the single-dose \& the multiple dose antibiotic prophylaxis group and antibiotics for five days postoperatively group.

Sadraei-Moosavi, et al. ${ }^{6}$ from Babol city, Iran showed similar results for SSI following NPA among two samples; one receiving antibiotics (ceftriaxone and metronidazole) only preoperatively and the other receiving both pre and 24 hours postoperatively. SSI was developed in one patient in each group.

Le, et al. ${ }^{7}$ from Salt Lake city, USA concluded that the frequency of SSIs is not decreased by using postoperative antibiotics in cases having NPA, while it usually increases the cost of treatment.

Kasatpibal, et al. ${ }^{8}$ collected data of appendectomies from eight hospitals of Thailand from July 1, 2003 to June 30, 2004 and found 26 (1.22\%) cases with SSI.

Shira, et al. ${ }^{9}$ from Madina city in Saudi Arabia reported for the period from January 2010 to December 2014 similar rate of SSI following NPA in patients who received only preoperative antibiotics and the patients who received both preoperative plus three doses of same antibiotics postoperatively.

Tiono, et al. ${ }^{10}$ from Bali, Indonesia from April to June 2012 showed similar results for risk of SSI among single-dose and multiple-dose antibiotic prophylaxis in NPA.

van Rossem, et al. ${ }^{11}$ from Hilversum city, North Holland province, Netherland concluded that three and five days of antibiotic regimen are similarly effective in reducing SSI following appendectomies for complicated appendicitis.

1.2 Research Problem (RP), Knowledge Gap (KG) \& Research Question (RQ): There are many international and national studies, which show effect of preoperative injectable antibiotics in reducing rate of SSI in appendectomy patients but none are showing the effect of postoperative oral antibiotics. The lack of this information regarding our population is our research problem and unavailability of this piece of information is our knowledge gap. The current practice in our hospital and other district hospitals is to prescribe oral antibiotics at discharge for five days in addition to perioperative injectable antibiotics.

Whether incorporation of postoperative oral antibiotics helps in reducing the frequency of SSI in our population? We have to answer this research question, fill up the gap and thereby solve the problem.

1.3 Research Objective: The objective of this trial was to compare the efficacy of post-operative oral antibiotics versus placebo in reducing the frequency of surgical site infection (SSI) following appendectomy for non-perforated appendicitis in population of South Waziristan Agency, Pakistan.
1.4 Research (null) Hypothesis $\left(\mathrm{H}_{0}\right)$ : The efficacy of post-operative oral antibiotics is similar to placebo in reducing the frequency of surgical site infection (SSI) following appendectomy for non-perforated appendicitis in population of South Waziristan Agency, Pakistan.

1.5 Significance and applicability of the trial: If the addition of post-operative oral antibiotics doesn't offer any additional benefit in term of reduction in frequency SSI, then it can be recommended to avoid prescribing oral antibiotics on discharge to appendectomy patients. This will not only reduce financial burden on the patients but will also aid in reducing antibiotics resistance in the community.

\section{MATERIALS AND METHODS}

2.1 Design, Setting \& Duration: This randomized control trial (RCT) was conducted at Agency Headquarter Hospital, Wana, South Waziristan Agency (SWA), Pakistan from October 1, 2016 to November 18,2018 . Approval was granted by hospital authorities and informed consent was taken from the patients/ their attendants.

2.2 Sampling \& Randomization: All patients older than 10 years with clinical diagnosis of acute appendicitis were included in this trial. Those cases who had received antibiotics within 72 hours of admission, diabetic or were found to have perforated or gangrenous appendix or mass and abscess formation were excluded from trial. One hundred fifty (150) patients were randomly allocated by lottery method into two groups, 75 in experimental group, to whom postoperative oral antibiotics were given and 75 in placebo group, to whom antibiotics were not given.

2.3 Procedure, Intervention and Follow up: All the patients were given injection ceftriaxone $1 \mathrm{gm}$ and metronidazole $500 \mathrm{mg}, 30 \mathrm{~min}$ before surgery and postoperatively for 24 hours in standard recommended dose. The experimental group received 1 gm co-amoxiclave tablets two times for 5 days while placebo group received tablets of the same size, of multivitamins twice daily for five days.

All patients underwent open appendectomy under general anesthesia by a single surgeon via gridiron incision with primary wound closure. They got discharged after 24 hours once they became mobile, pain got relieved on oral analgesics and start tolerating soft diet. All patients were advised to get their first follow up visit in surgical outdoor on $10^{\text {th }}$ postoperative day, next one week later and then at $30^{\text {th }}$ postoperative day. Patients were educated regarding signs of surgical site infection and were advised to come to emergency if they developed any. Surgical site infection definition by centers for disease placebo and prevention (CDC) was used in all cases. Infected wounds were managed by daily wound lavage with normal saline and laying open of wound followed by secondary closure. 
2.4 Data collection \& analysis plan: Sex (men/ women) and age groups (10-15, 16-39 \& $\geq 40$ years) were matching variables, while presence of SSI (yes/ no) was a research variable. Sex and presence of SSI were on nominal scale, while age groups were on ordinal scale. The data for the sample was described by count and percentage. It was inferred to population as confidence interval at $80 \%$ confidence level. ${ }^{12}$ McNemar chi-square test was used to test hypothesis to see the significance of difference between the experimental and placebo groups in terms of frequency of SSI at alpha 0.05 with Yates correction for continuity using an online calculator. ${ }^{13}$

2.5 Marwat logical Trajectory of Research Process: We have used this hierarchy of enquiry in our project. It is an innovative 8-steps logical model for research projects. ${ }^{14-15}$ McNemar chi-square test is explained in detail in the two cited books ${ }^{16-17}$ and two cited articles. ${ }^{18-19}$

\section{RESULTS}

Out of 75 patients in experimental group, 40 (53.34\%) were men \& 35 (46.66) women. Out of 75 patients in placebo group, 36 (48\%) were men \& 39 (52\%) women.

There were 20 (26.66\%) patients in age group 10-15 years, $49(65.34 \%)$ in $16-39$ years and six (8\%) in age group $\geq 40$ years in experimental group, while there were $10(13.34 \%)$ patients in age group $10-15$ years, $56(74.66 \%)$ in $16-39$ years, while nine $(12 \%)$ in age group $\geq 40$ years in placebo group.

The SSI was present in nine $(12 \%, 80 \% \mathrm{Cl} 7.19$ $16.80 \%)$ cases and absent in $66(88 \%, 80 \% \mathrm{Cl} 83.19$ $92.80 \%$ ) cases in experimental group, while it was present in $12(16 \%, 80 \% \mathrm{Cl} 10.57-21.42 \%)$ cases and absent in $63(84 \%, 80 \% \mathrm{Cl} 78.57-89.42 \%)$ cases in placebo group.

McNemar chi-square test showed p-value of .2482 (less than alpha). The null hypothesis was accepted, showing no significant difference between the two groups.

\section{DISCUSSION}

Our trial showed surgical site infection (SSI) in 12\% $(80 \% \mathrm{Cl} 7.19-16.80 \%)$ cases in experimental group (five days postoperative oral antibiotics) and 16\% $(80 \% \mathrm{Cl} 10.57-21.42 \%)$ in placebo group. The difference was statistically non-significant $(p=.2482)$.

Amongst many factors affecting the rate of SSI after appendectomy, antibiotics is an important one, with their positive role being well established while using pre-operatively but controversial in postoperative settings for non-perforated appendectomy (NPA).

Coakley, et al. ${ }^{3}$ found no difference in frequency of $\mathrm{SSI}$ is 334 cases who took postoperative antibiotics and 394 who did not. Postoperative antibiotics were associated with higher rates of UTI, diarrhea, and longer length of stay and higher readmission and reoperation rates.

Rafiq, et al. ${ }^{4}$ from Peshawar, Pakistan for the period from November 11, 2012 to May 30, 2014 did not find any statistical significant difference $(p=.65)$ in rate of SSI for non-perforated appendectomies $(n=192)$ treated with single preoperative dose of antibiotics (cefuroxime sodium and metronidazole) with SSI in $15(7.8 \%)$ and those treated with both single dose of pre and single dose of postoperative antibiotics $(n=198)$ with SSI in $18(9.1 \%)$ cases.

Mui, et al. ${ }^{5}$ conducted an RCT in Hong Kong, the rate of SSI after open appendectomy for NPA was not significantly different amongst three antibiotic regimens i.e. the single-dose $(6.5 \%)$ \& the multiple dose antibiotic prophylaxis group (6.4\%) and the group who used antibiotics for five days postoperatively (3.5\%)..$^{9}$ One reason to this difference in SSI rate could be type antibiotic used for prophylaxis. We used co-amoxiclav, while cefuroxime was used in Mui, et al. ${ }^{5}$ study.

Sadraei-Moosavi, et al. ${ }^{6}$ from Babol city, Iran from October 2013 to October 2014 showed similar results for SSI following NPA among two groups; one group $(n=76)$ receiving antibiotics (ceftriaxone and metronidazole) only preoperatively $(n=76)$ and the

Table 1: Efficacy of post-operative oral antibiotics versus placebo in reducing the frequency of surgical site infection (SSI) following appendectomy for non-perforated appendicitis in population of South Waziristan Agency, Pakistan ( $\mathrm{n}=75$ pairs)

\begin{tabular}{|c|c|c|c|c|c|c|c|}
\hline \multirow{2}{*}{\multicolumn{2}{|c|}{ Presence of SSI }} & \multicolumn{2}{|c|}{ Experimental group $(\mathrm{n} 1=75)$} & \multirow{3}{*}{$\begin{array}{c}\text { Columns Total } \\
12\end{array}$} & \multirow{4}{*}{\begin{tabular}{|c} 
Chi-square value \\
1.333
\end{tabular}} & \multirow{4}{*}{\begin{tabular}{|c|} 
d.f. \\
1 \\
\end{tabular}} & \multirow{3}{*}{$\begin{array}{r}\mathrm{p} \text {-value } \\
.2482\end{array}$} \\
\hline & & \multirow{2}{*}{$\begin{array}{c}\text { SSI Yes } \\
\text { (a) } 8\end{array}$} & \multirow{2}{*}{$\begin{array}{l}\text { SSI No } \\
\text { (c) } 04\end{array}$} & & & & \\
\hline \multirow{2}{*}{$\begin{array}{l}\text { Placebo group } \\
(\mathrm{n} 1=75)\end{array}$} & SSI Yes & & & & & & \\
\hline & SSI No & (b) 1 & (d) 62 & 63 & & & \\
\hline \multicolumn{2}{|l|}{ Rows Total } & 9 & 66 & 75 Pairs & \multicolumn{3}{|c|}{$\mathrm{H}_{0}$ accepted at alpha .05} \\
\hline
\end{tabular}


other group $(n=76)$ receiving the same antibiotics both pre and 24 hours postoperatively.

Le, et al. ${ }^{7}$ from Salt Lake city, USA found similar results for all SSIs in two groups; one which used and the other which did not use postoperative antibiotics in patients undergoing NPA ( $10 \%$ vs. $9 \%, p=.64$ ).

Shira, et al. ${ }^{9}$ from Madina city in Saudi Arabia reported 482 cases of NPA for the period from January 2010 to December 2014. The rate of SSI was $7.17 \%\left(17^{*} 100 / 237=7.17\right)$ in patients who received only preoperative antibiotics (cefazoline 1 gram and metronidazole 500 milligram) and $8.16 \%$ $(20 * 100 / 245=8.16)$ in those who received both preoperative plus three doses of same antibiotics postoperatively (cefazoline 500 milligram and metronidazole 500 milligram every 8 hours), with no significant difference $(p=.9182)$.

Tiono, et al. ${ }^{10}$ from Bali, Indonesia from April to June 2012 showed similar results for risk of SSI among single-dose (SSI in 7.3\%) and multiple dose (SSI in $5.5 \%$ ) antibiotic prophylaxis in NPA. Both the groups were given cefazolin $1 \mathrm{~g}$ and metronidazole $500 \mathrm{mg}$ preoperatively. Postoperatively single dose group $(n 1=55)$ was given placebo and multiple-dose group $(n 2=55)$ was given two additional doses of same antibiotics.

\section{CONCLUSION}

The results are comparable for post-operative oral antibiotics versus placebo in reducing the frequency of surgical site infection (SSI) following appendectomy for non-perforated appendicitis in population of South Waziristan Agency, Pakistan. It can be recommended that there is no additional benefit by continuing further doses of oral antibiotic in preventing SSI. So, for surgeons it is essential to update their routine practice of antibiotic use according to the standard guidelines and evidence based medicine rather than irrational use of antibiotics.

Acknowledgement: All authors are thankful to Dr. Muhammad Marwat to grant us permission to adopt his "Marwat Logical Trajectory of Research Process" in ours this project.

\section{REFERENCES}

1. Williams RS, Wilson SE. Appendicitis. In: Howard RJ, Simons RL, eds. Surgical Infectious Disease. 3rd ed. Norwalk, CT: Appleton and Lange; 1995.

2. Bahar MM, Jangjoo A, Amouzeshi A, Kavianifar K. Wound infection incidence in patients with simple and gangrenous or perforated appendicitis. Arch Iran Med 2010 Jan 1;13(1):13-6.

3. Coakley BA, Sussman ES, Wolfson TS, Bhagavath AS, Choi JJ, Ranasinghe NE, et al. Postoperative antibiotics correlate with worse outcomes after appendectomy for nonperforated appendicitis. J Am Coll Surg 2011;213(6):778-83. https:// doi.org/10.1016/j.jamcollsurg.2011.08.018
4. Rafiq MS, Khan M, Khan A, Jan H. Evaluation of postoperative antibiotics after non-perforated appendectomy. J Pak Med Assoc 2015 Aug 1;65(8):815-7.

5. Mui LM, Ng CS, Wong SK, Lam YH, Fung TM, Fok KL, et al. Optimum duration of prophylactic antibiotics in acute nonperforated appendicitis. ANZ J Surgery 2005 Jun;75(6):425-8. https://doi. org/10.1111/j.1445-2197.2005.03397.x

6. Sadraei-Moosavi SM, Nikhbakhsh N, Darzi AA. Postoperative antibiotic therapy after appendectomy in patients with non-perforated appendicitis. Caspian J Intern Med 2017;8(2):104-7.

7. Le D, Rusin W, Hill B, Langell J. Post-operative antibiotic use in nonperforated appendicitis. Am J Surg 2009;198 (6):748-52. https://doi. org/10.1016/j.amjsurg.2009.05.028

8. Kasatpibal N, Nørgaard M, Sørensen HT, Schønheyder $\mathrm{HC}$, Jamulitrat $\mathrm{S}$, Chongsuvivatwong V. Risk of surgical site infection and efficacy of antibiotic prophylaxis: a cohort study of appendectomy patients in Thailand. BMC Infect Dis 2006 Dec;6(1):1-7. https://doi.org/10.1186/14712334-6-111

9. Shirah $B H$, Shirah HA. Wound infection in non-perforated acute appendicitis-single dose preoperative antibiotics vs. prophylactic postoperative antibiotics: does it make any difference. Int J Res Med Sci 2016 Jan;4(1):225-30. https:// doi.org/10.18203/2320-6012.ijrms20160035

10. Tiono BG, Sudartana K, Widiana R. There is no difference of surgical site infection between single-dose and multiple-dose of prophylaxis antibiotic in open appendectomy of non-perforated acute appendicitis. Bali Medical Journal. 2012;1(3):121-4.

11. van Rossem CC, Schreinemacher MHF, Treskes K, van Hogezand R M, van Geloven AA W. Duration of antibiotic treatment after appendicectomy for acute complicated appendicitis. British J Surg 2014 May;101(6):715-9. https://doi.org/10.1002/ bjs. 9481

12. Statistics Kingdom. Proportion confidence interval calculator [internet]. Statistics Kingdom; Melbourne, Australia 2007. [accessed 2020 Apr 25]. Available at: http://www.statskingdom. com/41_proportion_confidence_interval.html

13. Motulsky HJ. GraphPad, QuickCalcs. McNemar's test to analyze experimental studies [accessed 2020 Apr 25]. GraphPad Software, San Diego, CA, USA. Available at: https://www.graphpad. $\mathrm{com} /$ quickcalcs/McNemar1.cfm

14. Marwat M, Ahmad I, Ashiq F, Ali S, Zamir S, Rehman MU, et al. Frequency, distribution and determinants of diabetes mellitus in adult acute coronary syndrome population of D.I.Khan Division, Pakistan. Gomal J Med Sci 2019 OctDec; 17 (4):131-43. https://doi.org/10.46903/ gjms/17.04.2106

15. Ain N, Khan S, Marwat M, Khan N, Ahmad I, 
Ramzan F, et al. Frequency, distribution and determinants of hypertension in adult stroke population of D.I.Khan Division, Pakistan. Gomal J Med Sci 2019 Jul-Sep; 17 (3):81-9. https://doi. org/10.46903/gjms/17.03.2076

16. Zar JH. Biostatistical Analysis. 5th ed. Englewood Clifts, New Jersey: Prentice-Hall, Inc. p.127.

17. Pegano M, Gauvreau K. Principals of Biostatistics. 2nd ed. Boston, MA, USA: Cengage Learning; 2000. p.349-52.

18. Shah HU, Gul H, Khan R, Marwat M. Urethrocu- taneous fistula following Snodgrass versus two stage Aivar Bracka repair of distal penile hypospadias in male children: a randomized control trial. Gomal J Med Sci 2018;16:54-8. https://doi. org/10.46903/gjms/16.02.1284

19. Butt M, Rehman MU, Khan AR, Abrar A. Frequency of triple-vessel coronary artery disease in adult type 2 diabetics versus non-diabetics in coronary artery disease population of Islamabad, Pakistan. Gomal J Med Sci 2019 Apr-Jun;17(2):37-41. https://doi.org/10.46903/gjms/17.02.2029

\section{AUTHORS' CONTRIBUTION}

The following authors have made substantial contributions to the manuscript as under:

\section{Conception or Design:}

Acquisition, Analysis or Interpretation of Data:

Manuscript Writing \& Approval:

All the authors agree to be accountable for all aspects of the work in ensuring that questions related to the accuracy or integrity of any part of the work are appropriately investigated and resolved. 